\title{
An experimental study of live-bed scour at circular pier in covered flow
}

\author{
O. Lauva \\ Riga Technical University, Dept. of Water Engineering and Technology, Riga, Latvia
}

A. Radice

Politecnico di Milano, Dept. of Civil and Environmental Engineering, Milan, Italy

\begin{abstract}
Live-bed scour at a bridge pier in covered flow was experimentally investigated. The laboratory campaign also comprehended a clear-water run and preliminary tests (without the pier) that were performed to characterize the pattern of the bed-forms developing in the channel. Fixed-point measurements of the bed elevation were obtained for all the runs with a laser distance sensor. The maximum scour depth and the equilibrium time decreased for increasing flow velocity; these results are in agreement with the typical depictions of the process for open-channel flows. It must be however noted that equilibrium conditions were not achieved in the clear-water run. An analysis of the dune properties (length, height) was performed based on the results of the preliminary tests, and a comparison with literature predictors showed variable levels of agreement. The fluctuations of the scour depth after equilibrium were compared to the oscillations of the bed elevation related with the bedforms. Additional experiments in different conditions and with longer duration are presently under design.
\end{abstract}

\section{BACKGROUND}

Experimental studies on local scour available in the literature have been mainly focused on clear-water (CW) scour conditions, where the average flow velocity, $U$, is smaller than the critical flow velocity, $U_{c}$, for the initiation of sediment motion. In reality, however, the situation is quite the opposite: scour around bridge piers and abutments takes place under live-bed (LB) scour conditions $\left(U>U_{c}\right)$ and the scour process is the combination of sediment erosion and refill of the scour hole from upstream. $\mathrm{CW}$ scour experiments are preferred to LB experiments due to a more simple configuration of the facilities. Furthermore, a typical depiction of the process shows that the maximum scour depth is reached at the limiting $\mathrm{CW}$ conditions (i.e. $U \approx U_{c}$ ) whereas the expected scour depth in live-bed conditions will be smaller, due indeed to hole refill by the upstream sediment transport, even though a second peak in depth might be found for very high transport intensities (e.g., Melville, 1997 among many others).

LB scour at bridge piers has been investigated in several works, e.g., Melville (1984), Fischer \& Jain (1987), Chiew (1993), Kothyari et al. (1993), Melville (1993), Sheppard \& Miller (2006), Tafarojnoruz et al. (2012), Hong et al. (2014), and Ettmer et al. (2015). Live-bed experiments have been also conducted with reference to marine structures, such as offshore wind farms, in most cases accounting for oscillatory flows (Whitehouse et al., 2011, Petersen et al., 2012, and Sumer et al., 2013). However, all these studies have considered free-surface conditions, as the most typical ones for rivers and coastal areas. To the best of our knowledge, no studies on LB scour at piers in covered flow are available in the scientific literature. Analyses of CW scour in covered flow (considered prototypal of ice-covered rivers) were instead performed and results were compared to analogous ones for free-surface conditions, finding that scour depths in covered flows were slightly larger than those with a free surface (e.g., Hains \& Zabilansky, 2004, Radice et al., 2009, and $\mathrm{Wu}$ et al., 2016). This is likely due to the fact that the upper boundary layer makes the flow concentrate closer to the sediment bed. Some arguments in this respect were also given by Radice \& Tran (2012).

In this paper we present results from LB scour experiments conducted in covered flow with a circular pier. Preliminary tests were performed (without the pier) to characterize the pattern of developing bedforms. A CW run was also carried out as representative of a benchmark scour level for comparison with depths from the LB tests.

\section{EXPERIMENTS}

The experiments reported herein were run at the Hydraulics Laboratory "G. Fantoli" of the Politecnico 
di Milano, Italy. We used a rectangular closed conduit, $5.8 \mathrm{~m}$ long, $0.40 \mathrm{~m}$ wide and $0.16 \mathrm{~m}$ high. The bottom was covered with a layer of PBT grains, having median diameter $d_{50}=3.0 \mathrm{~mm}$ and density $\rho_{s}=$ $1.27 \mathrm{~kg} / \mathrm{dm}^{3}$.

Preliminary runs were performed to determine the threshold flow velocity corresponding to the incipient motion of sediment. The sediment layer had a thickness of $3 \mathrm{~cm}$ during these runs. Starting from a low flow rate for which no particle motion was observed, the discharge was progressively increased until the critical conditions were reached and then exceeded. The threshold condition was quantitatively predetermined (following Radice \& Ballio, 2008) as that corresponding to a dimensionless sediment transport rate per unit width of $6 \times 10^{-5}$. The solid discharge was measured counting the number of particles passing over a plate in a given time duration. The critical flow rate was $13.2 \mathrm{l} / \mathrm{s}$.

Other preliminary runs were executed to characterize the pattern of developing bedforms with two different discharges $\left(Q / Q_{c}=1.2\right.$ and 1.4, where $Q=$ flow discharge and $Q_{c}=$ threshold discharge for incipient motion of the bed sediment). Both water and sediment were recirculated: water was conveyed by the facility circuit, while sediment was manually taken out from a sediment catcher in an outlet tank of the channel and placed into a sediment feeder located above the first section of the channel. A laser distance sensor was used to measure the temporal evolution of the bed elevation at $4 \mathrm{~m}$ from the inlet. Sediment feeding rates were adjusted in order to preserve the mean bed elevation, thus avoiding general aggradation or degradation, and were equal to $7.8 \times 10^{-7}$ and $6.2 \times 10^{-6} \mathrm{~m}^{2} / \mathrm{s}$ for the two hydrodynamic conditions, respectively.

A recess section enabled scour holes to be formed by the flow impacting a pier model during scour tests. The pier used in this work was a telescopic PVC cylinder with $6 \mathrm{~cm}$ diameter, that was placed at $4.5 \mathrm{~m}$ from the inlet of the channel, to ensure development of the flow and morphologic features. The pier diameter was $15 \%$ of the conduit width; contraction scour was never observed, consistently with literature indication according to which the ratio of pier size to flume width would significantly impact the scour levels for relatively large values (for example, Breusers \& Raudkivi, 1991, provided a threshold value of 0.4 ). The cylinder consisted of two parts. The upper part could slide into the lower part, which formed a jacket for the upper part, so that the cylinder could be completely buried in the sediment bed. Prior to the execution of a scour test, uniform flow conditions were achieved with the cylinder sank under the bed surface, to allow for adjustment of initial conditions for scour. Before the start of the actual scour test, continuous measurements of the bottom elevation were taken at a fixed point $1 \mathrm{~cm}$ upstream of the face of the cylinder, in
Table 1. Bedform test results.

\begin{tabular}{lllllll}
\hline Test & $Q$ & $Q / Q_{c}$ & $T$ & $\begin{array}{l}\Delta_{D} \\
{[\mathrm{~mm}]}\end{array}$ & $\begin{array}{l}\lambda_{D} \\
{[\mathrm{~mm}]}\end{array}$ & $\begin{array}{c}T_{D} \\
{[\mathrm{~s}]}\end{array}$ \\
\hline BF1 & 15.8 & 1.2 & 22,200 & $-*$ & $-*$ & $-*$ \\
BF2 & 18.4 & 1.4 & 5,700 & 20 & 830 & 713 \\
\hline
\end{tabular}

* No evident bedforms.

order to determine the reference average nonscoured bed level. Once a stable initial condition was set, the upper part of the cylinder was rapidly lifted up, out of the sediment bed, thus initiating the scour process. The measurement of the bed elevation upstream of the pier was continued during this experimental phase. Frequent measurements of the water discharge were made by a magnetic flow-meter in order to verify the maintenance of constant conditions in the channel.

The LB experiments with the cylindrical pier were carried out with the same flow rates $(Q=15.8$ $1 / \mathrm{s}$ and $18.41 / \mathrm{s}$ corresponding to $Q / Q_{c}=1.2$ and 1.4 ) that were previously used for the preliminary experiments with bedform development in the absence of the obstacle. The laboratory campaign also included a CW run with a discharge of $11.91 / \mathrm{s}\left(Q / Q_{c}=0.9\right)$ that was used as a benchmark for comparison with the LB tests.

\section{RESULTS OF PRELIMINARY TESTS FOR BEDFORMS}

Details of the preliminary runs for bedform development are listed in Table 1, where $T$ is the duration of the experiment. For the LB experiment with $Q / Q_{c}$ $=1.2$, bedforms were not observed, the sediment transport taking place with a plane-bed condition. This is in agreement with earlier experimental campaigns performed in the same facility (e.g., Campagnol et al., 2015, where the bed remained flat until $Q / Q_{c}=1.3$ that was the largest transport condition investigated).

For $Q / Q_{c}=1.4$, the sediment bed started to evolve and change from smaller bedforms (ripples) to bigger ones (dunes) until stable conditions were reached. Figure 1 depicts the time series of fluctuations of the bed elevation around the mean value. A relatively regular patterns can be observed, from which the value of $\Delta_{D}$ as the dune height was estimated as an approximation of the maximum difference between crests and troughs. The period of dunes, $T_{D}$, was preliminarily estimated by counting the number of observed bedforms and dividing it by the test duration. The length of the dunes, $\lambda_{D}$, could not be obtained from the temporal measurements and was independently measured by a meter during the experiment. A celerity of propagation of the dunes could then be estimated as $c=\lambda_{D} / \Delta_{D}=1.2$ $\mathrm{mm} / \mathrm{s}$. A conceptual model of dune propagation indicates that the volume of one dune, $W_{D}=$ 
$0.5 \times \lambda_{D} \times \Delta_{D} \times B$ (with $B$ as the width of the conduit) would pass through any transverse section in a time equal to $T_{D}$, resulting in a sediment transport discharge $Q_{s}=0.5 \times \lambda_{D} \times \Delta_{D} \times B \times(1-p) / T_{D}$, with $p$ as porosity. According to this, another estimator of the dune celerity is $c=2 \times Q_{s} /\left[B \times \Delta_{D} \times(1-p)\right]$. Considering the feeding rate used in the experiment and a tentative value of $p=0.4$, one obtains $c=1.0 \mathrm{~mm} / \mathrm{s}$. The two values obtained for the celerity of migration of the dunes are in agreement with each other. Therefore, even if the dune properties that have been roughly estimated here should be object of a more thorough evaluation, the results of independent measurements are consistent with the simple conceptual model and indicate a relationship between bedform height and celerity, similarly to what happens for water waves.

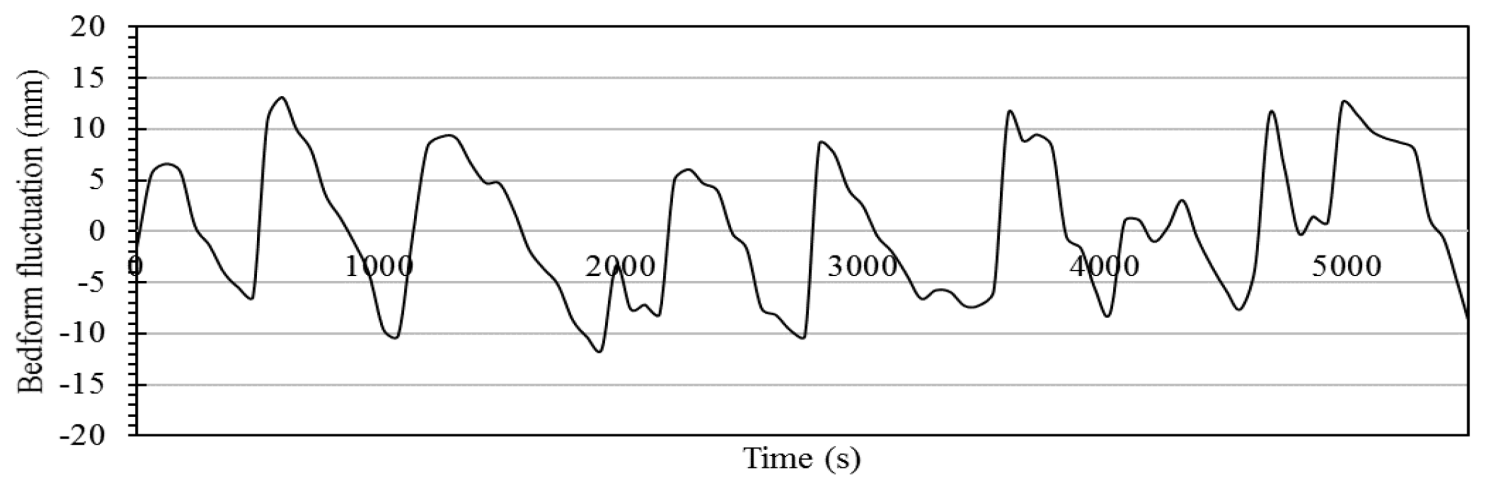

Figure 1. Bedform fluctuations around mean bed elevation for test BF2.

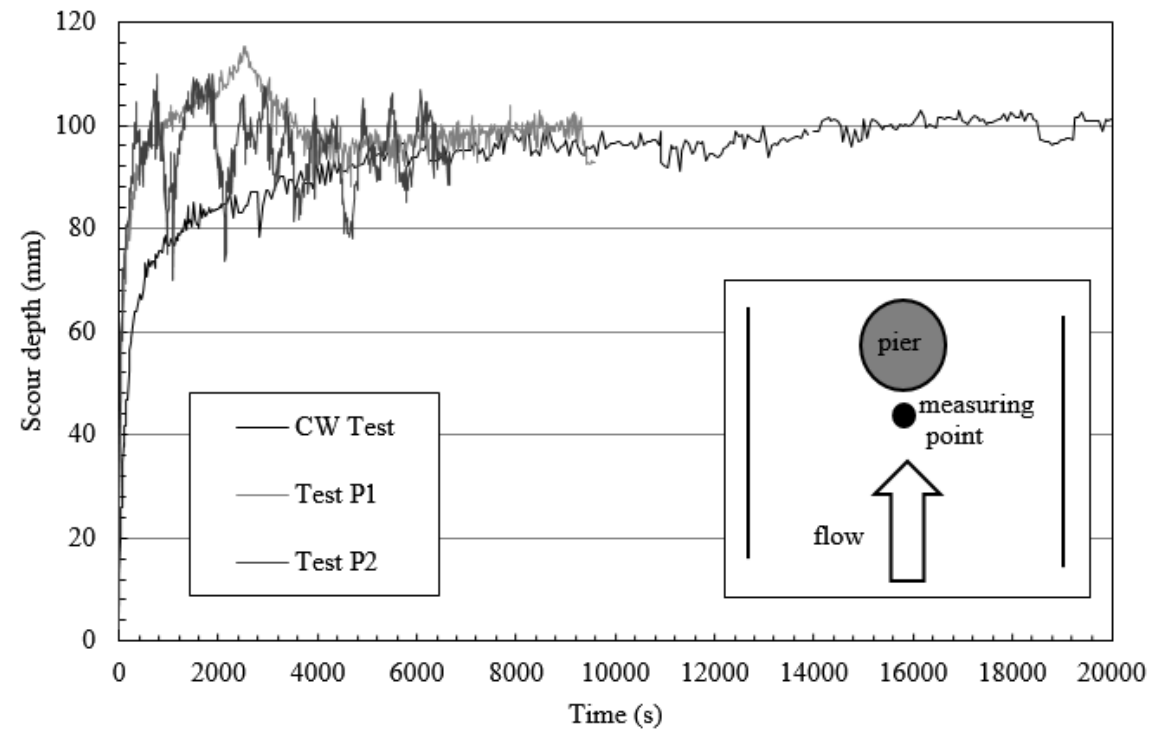

Figure 2. Scour evolution at pier for different flow rates.

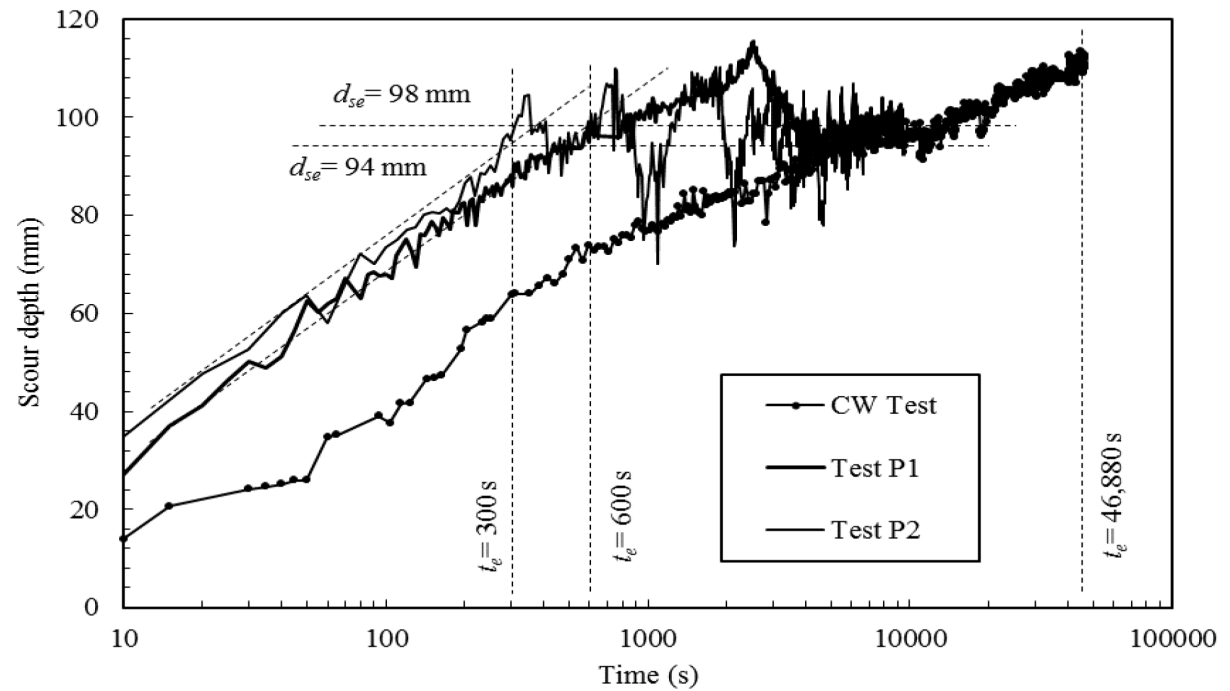

Figure 3. Scour evolution (with logarithmic time axis) and estimation of equilibrium time and scour depth. 
Table 2. CW and LB test results.

\begin{tabular}{llllll}
\hline Test & $Q$ & $Q / Q_{c}$ & $\begin{array}{l}T \\
{[\mathrm{~s}]}\end{array}$ & $\begin{array}{l}d_{s e} \\
{[\mathrm{~mm}]}\end{array}$ & $\begin{array}{l}t_{e} \\
{[\mathrm{~s}]}\end{array}$ \\
\hline CW & 11.84 & 0.9 & 46,880 & $112^{*}$ & $46,880^{*}$ \\
P1 & 15.78 & 1.2 & 9,580 & 98 & 600 \\
P2 & 18.40 & 1.4 & 6,670 & 94 & 300 \\
\hline
\end{tabular}

* The equilibrium was not achieved.

Bedform results from test BF2 were compared to several bedform height, length and period prediction tools available in the literature. It should be remarked here that available predictors are actually referred to open-channel flows rather than covered flows. Garcia (2008) mentioned that welldeveloped dunes tend to have wave heights $\Delta_{D}$ scaling up to about one-sixth of the flow depth $H$; i.e. $\Delta_{D} / H \leq 1 / 6$. Such a condition was verified in the present case, where $\Delta_{D} / H=20 / 140<1 / 6$. Julien \& Klaassen (1995) analyzed a large number of laboratory and field data and proposed a simple relation $\lambda_{D} / H=6.25$ as a reasonable first approximation for dune length, which reasonably fits the present results where $\lambda_{D} / H=830 / 140=5$.9. Julien $\&$ Klaassen (1995) also proposed an equation for dune height $\Delta_{D}=2.5 \times H \times\left(d_{50} / H\right)^{0.3}=111 \mathrm{~mm}$, which greatly exceeds the actual dune height value in test BF2. Finally, in Julien \& Klaassen's (1995) analysis, dune length was also described by $\lambda_{D}=$ $2.5 \times \Delta_{D} \times\left(H / D_{50}\right)^{0.3}$ that correctly predicts the measured value if the $111-\mathrm{mm}$ value is used for $\Delta_{D}$ instead of the measured one. A few more dune length calculation formulae can be found in the literature by Yalin (1964) and Van Rijn (1984), where dune lengths are expressed as $\lambda_{D}=2 \pi H$ and $\lambda_{D}=7.3 H$, respectively. These two predictors are similar to that from Julien \& Klaassen (1995).

Reasonable prediction of our bedform features by formulae developed for open-channel flow would point at similar bedform initiation mechanisms for subcritical open-channel flow and closed-conduit flows. This finding confirms, for example, the indications of the theoretical analyses of Engelund \& Fredsøe (1982), although the phenomena responsible for bedform creation remain to be determined. Yalin (1977) argued that the formation of dunes may be caused by the large-scale oscillations. Large, but low-frequency, eddies appear at a relatively regular interval, resulting in decrease and increase in bed shear stress. This is the reason for local deposition and erosion of sediment particles on leeside and stoss side, respectively. Yalin explained the decrease and increase in bed shear stress corresponding to near-bed decrease and increase (with respect to standard distribution) in velocity gradients.

On another hand, differences between rates of bed-form development for closed-conduit flows and equivalent open-channel flows have been observed, in that closed-conduit bed forms develop much more rapidly (Coleman et al., 2003). These differences in growth rates for bed forms in openchannel and closed-conduit flows have been explained to arise due to how these respective flows respond to the increasing bed roughness associated with the growing bed forms.

\section{RESULTS OF SCOUR TESTS}

Figure 2 depicts the measured scour depth evolution in time for the two different LB tests and the $\mathrm{CW}$ one. The two LB runs are much shorter than the $\mathrm{CW}$ experiment, since it was more difficult to maintain stationary conditions for these tests (due to loss of sediment through the downstream catcher). The LB test P1 at $Q / Q_{c}=1.2$ was run for approximately 2 hours and 40 minutes; after that the pier was pushed back into the jacket, the discharge was set to $Q / Q_{c}=1.4$ and the channel was let to run for 1 hour in order for the sediment to fill the scour hole and allow the bedforms to fully develop to equilibrium; then, the pier was pulled out again and the second pier test, P2, lasted for approximately 1 hour and 50 minutes. The $\mathrm{CW}$ test was run for 13 hours; however, the equilibrium was not reached within this duration. Results of $L B$ and $\mathrm{CW}$ pier scour tests can be seen in Table 2, where $d_{s e}=$ equilibrium scour depth; and $t_{e}=$ equilibrium time of scour. For tests P1 and P2 the equilibrium time $t_{e}$ was easily and robustly estimated (Fig. 3) following this method: (1) the mean equilibrium scour depth was determined by drawing a horizontal line in the equilibrium phase (for test P1 the average scour depth was $d_{s e}=98 \mathrm{~mm}$, while for test P2 $d_{s e}=94 \mathrm{~mm}$ ); then, (2) a line was drawn fitting the scour data in the rising phase, and its interception with the line representing equilibrium scour depth was used to find the equilibrium time of scour (for test P1 $t_{e}=600 \mathrm{~s}$, for test P2 $t_{e}=300 \mathrm{~s}$ ). Since the equilibrium was not achieved in the $\mathrm{CW}$ test, time $t_{e}$ in Table 2 corresponds to the total duration of the test, and scour depth $d_{s e}$ is the scour depth at the end of the test.

Our LB experiments were characterized by a similar behaviour in the development phase before they reached the equilibrium stage. As the ratio $U / U_{c}$ increased, the equilibrium was reached in a shorter time (see again Fig. 3) and with decreasing scour depth value $d_{s e}$.

Also for the scour runs, for the condition of $Q / Q_{c}=1.2$ oscillations were not evident. Therefore, the scour oscillations after equilibrium were analyzed for test P2 and are depicted in Fig. 4. Comparison of Figs. 4 and 1 highlights that, for this hydrodynamic condition, fluctuations of the scour depth were characterized by similar amplitude and period to those of bedforms $\left(\Delta_{D}=20 \mathrm{~mm}\right.$ and $T_{s}=713 \mathrm{~s}$, see also Table 1). Nevertheless, the 


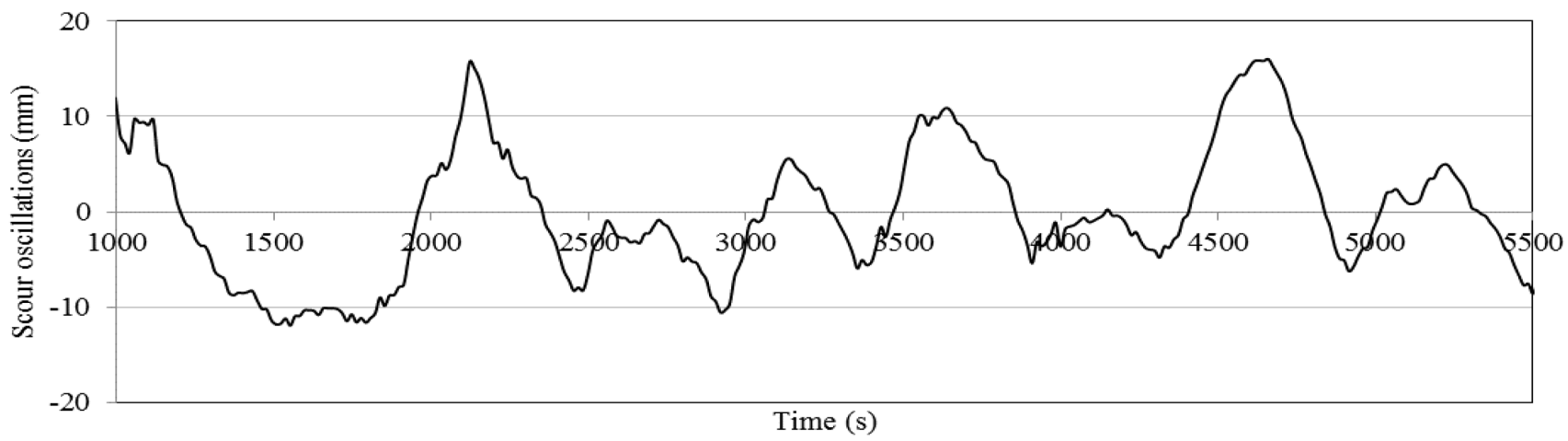

Figure 4. Scour oscillations around equilibrium value for test P2.

shape of the oscillations was different in the two cases, since the front of the dunes was much steeper than the tail whereas the scour fluctuations were approximately symmetric. It was therefore shown that the passage of bedforms through the erosion hole determined a deformation of these geometric features. This effect was related with the fact that, when a dune reached the edge of the erosion hole, it determined an avalanche of sediment, temporarily depositing at the hole bottom before it was eroded again by the action of the vortex system.

\section{CONCLUSIONS}

The results of live-bed scour experiments with a cylindrical pier were presented. To our knowledge, this was the first time that such experiments were performed with a covered flow. In the development phase, the scour evolution is similar to clear-water experiments, with increasing scour rates for increasing flow intensities; time to reach equilibrium, on the contrary, decreases rapidly for increasing flow intensities. These findings were qualitatively similar to typical depictions of the scour process in open-channel flows, but quantitative comparisons of scour values for open-channel flow and covered flow available in the literature (only for clear-water conditions) showed that the covered-flow condition can induce slightly larger scour values.

We also performed an analysis of the dune properties (length, height, period and celerity) based on the results of preliminary tests, and a comparison with literature predictors showed variable levels of agreement. Oscillations of the scour depth after equilibrium were compared to fluctuations of the bed elevation related with bedforms, finding similar amplitude and period but different shape.

Follow-up work will include (i) realization of additional experiments to investigate experiment repeatability and other hydrodynamic conditions, (ii) a more thorough investigation of the bedform and scour fluctuations taking advantage of signalprocessing methods, and (iii) a comparison of the scour values with literature data and predictors for live-bed scour in open channels, to extend the comparison between open-channel flow and covered flow to live-bed conditions.

\section{ACKNOWLEDGMENTS}

The stay of the first writer at the Politecnico di Milano was financially supported by the ERASMUS+ program. Veronica Negrini is acknowledged for participating to the preliminary tests within her B.Sc. thesis.

\section{REFERENCES}

Breusers, H.N.C., and Raudkivi, A.J. (1991). Scouring. Balkema, Rotterdam, The Netherlands.

Campagnol, J., Radice, A., Ballio, F., and Nikora, V. (2015). Particle motion and diffusion at weak bed load: accounting for unsteadiness effects of entrainment and disentrainment. J. Hydraul. Res., 53(5), 633-648.

Chiew, Y.-M. (1993). Live-bed scour around cylindrical bridge piers. J. Hydraul. Res., 31(2), 279-281.

Coleman, S. E., Fedele, J. J., and Garcia, M. H. (2003). Closed-conduit bed-form initiation and development. $J$. Hydraul. Eng., 129(12), 956-965.

Engelund, F. A., and Fredsøe, J. (1982). Sediment ripples and dunes. Annu. Rev. Fluid Mech., 14, 13-37.

Ettmer, B., Orth, F., and Link, O. (2015). Live-bed scour at bridge piers in a lightweight polystyrene bed. J. Hydraul. Eng., 141(9), 04015017.

Fischer, E., and Jain, S. C. (1987). Live-bed scour at bridge piers. J. Hydraul. Eng., 113(3), 403-404.

Garcìa, M. H. (2008) Sediment transport and morphodynamics. In Sedimentation Engineering: Processes, Measurements, Modeling, and Practice Garcia, M. H. (ed). Manuals and reports on Engineering Practice No. 110, ASCE: Reston, VA, U.S.

Hains, D., and Zabilansky, L.J. (2004). Laboratory test of scour under ice: Data and preliminary analysis. U.S. Army Cold Regions Research and Engineering Laboratory (CRREL), TR-04-9, Hanover, N. H.

Hong, J. H., Wang, H. W., Wang, Y. C., Li, S. C., and Chiew, Y. M. (2014). Temporal evolution of live-bed pier scour. Proc. River Flow 2014, Lausanne, Switzerland, 1381-1386.

Julien, P. Y., and Klaassen, G. J. (1995). Sand-dune geometry of large rivers during floods. J. Hydraul. Eng., 121(9), 657-663. 
Kothyari, U. C., Garde, R. J., Ranga Raju, K. G., and Chiew, Y.-M. (1993). Live-bed scour around cylindrical bridge piers. J. Hydraul. Res., 31(2), 147-160.

Melville, B. W. (1984). Live-bed scour at bridge piers. $J$. Hydraul. Eng., 110(9), 1234-1247.

Melville, B. W. (1993). Live-bed scour around cylindrical bridge piers. J. Hydraul. Res., 31(5), 716-718.

Melville, B. W. (1997). Pier and abutment scour: integrated approach. J. Hydraul. Eng., 123(2), 125-136.

Petersen, T. U., Sumer, B. M., and Fredsøe, j. (2012). Time scale of scour around a pile in combined waves and current. Proc. $6^{\text {th }}$ Int. Conf. on Scour and Erosion, Paris, France.

Radice, A., and Ballio, F. (2008). Double-average characteristics of sediment motion in one-dimensional bed load. Acta Geophys., 56, 654-668

Radice, A., and Tran, C.K. (2012). Study of sediment motion in scour hole of a circular pier. J. Hydraul. Res., 50(1), 44-51.

Radice, A., Porta G., and Franzetti, S. (2009). Analysis of the time-averaged properties of sediment motion in a local scour process. Water Resour. Res., 45, W03401.

Sheppard, D. M., and Miller Jr., W. (2006). Live-bed local pier scour experiments. J. Hydraul. Eng., 132(7), 635642.

Sumer, B.M., Petersen, T. U., Locatelli, L., Fredsøe, J., Musumeci, R. and Foti, E. (2013). Backfilling of scour holes around piles. J. Waterway, Port, Coastal, Ocean Eng., 139(1), 9-23.

Tafarojnoruz, A., Gaudio, R., and Calomino, F. (2012). Bridge pier scour mitigation under steady and unsteady flow conditions. Acta Geophys., 60(4), 1076-1097.

Van Rijn, L. C. (1984). Sediment transport, Part III: Bed forms and alluvial roughness. J. Hydraul. Eng., 110(12), 1733-1754.

Whitehouse, R., Harris, J.M., Sutherland, J., and Rees, J. (2011). The nature of scour development and scour protection at offshore windfarm foundations. Mar. Pollut. Bull., 62(1), 73-88.

Wu, P., Balachandar, R., and Sui, Jueyi (2016). Local scour around bridge piers under ice-covered conditions. J. Hydraul. Eng., 142(1), 04015038.

Yalin, M. S. (1964). Geometrical properties of sand waves. $J$. Hydraul. Div., 90(5), 105-119.

Yalin, M. S. (1977). Mechanics of sediment transport. Pergamon Press, Inc., New York, NY, U.S. 